\title{
KCNA5 gene is not confirmed as a systemic sclerosis-related pulmonary arterial hypertension genetic susceptibility factor
}

\author{
Lara Bossini-Castillo ${ }^{1 *}$, Carmen P Simeon², Lorenzo Beretta ${ }^{3}$, Jasper Broen ${ }^{4,5}$, Madelon C Vonk ${ }^{6}$, José Luis Callejas ${ }^{7}$, \\ Patricia Carreira ${ }^{8}$, Luis Rodríguez-Rodríguez ${ }^{9}$, Rosa García-Portales ${ }^{10}$, Miguel A González-Gay ${ }^{11}$, Ivan Castellvi ${ }^{12}$, \\ María Teresa Camps ${ }^{13}$, Carlos Tolosa ${ }^{14}$, Esther Vicente-Rabaneda ${ }^{15}$ and María Victoria Egurbide ${ }^{16}$, for \\ the Spanish Scleroderma Group, Annemie J Schuerwegh ${ }^{17}$, Roger Hesselstrand ${ }^{18}$, Claudio Lunardi ${ }^{19}$, \\ Jacob M van Laar ${ }^{20}$, Paul Shiels ${ }^{21}$, Ariane Herrick ${ }^{22}$, Jane Worthington ${ }^{22}$, Christopher Denton ${ }^{23}$, \\ Timothy RDJ Radstake ${ }^{4,5}$, Carmen Fonseca ${ }^{23 \dagger}$ and Javier Martin ${ }^{1 \dagger}$
}

\begin{abstract}
Introduction: Potassium voltage-gated channel shaker-related subfamily member 5 (KCNA5) is implicated in vascular tone regulation, and its inhibition during hypoxia produces pulmonary vasoconstriction. Recently, a protective association of the KCNA5 locus with systemic sclerosis (SSC) patients with pulmonary arterial hypertension (PAH) was reported. Hence, the aim of this study was to replicate these findings in an independent multicenter Caucasian SSc cohort.

Methods: The 2,343 SSc cases (179 PAH positive, confirmed by right-heart catheterization) and 2,690 matched healthy controls from five European countries were included in this study. Rs 10744676 single-nucleotide polymorphism (SNP) was genotyped by using a TaqMan SNP genotyping assay.
\end{abstract}

Results: Individual population analyses of the selected KCNA5 genetic variant did not show significant association with SSC or any of the defined subsets (for example, limited cutaneous SSc, diffuse cutaneous SSc, anti-centromere autoantibody positive and anti-topoisomerase autoantibody positive). Furthermore, pooled analyses revealed no significant evidence of association with the disease or any of the subsets, not even the PAH-positive group. The comparison of PAH-positive patients with PAH-negative patients showed no significant differences among patients.

Conclusions: Our data do not support an important role of KCNA5 as an SSc-susceptibility factor or as a PAHdevelopment genetic marker for SSc patients.

\section{Introduction}

Systemic sclerosis (SSc) is a life-threatening fibrotic connective tissue disorder that affects the skin and different internal organs [1]. The 10-year survival of SSc patients reaches only $63 \%$, with pulmonary involvement the leading cause of death [2]. SSc is a complex disorder in which the environmental triggers and genetic susceptibility factors co-act in the development and maintenance of the disease

\footnotetext{
* Correspondence: larabc@ipb.csic.es

+ Contributed equally

'Instituto de Parasitología y Biomedicina López-Neyra, IPBLN-CSIC, Avenida del Conocimiento s/n, Granada, 18100, Spain

Full list of author information is available at the end of the article
}

[3]. As a clearer picture of the genetic component of this disease is being revealed, interest in genetic markers for specific clinical features, especially lung involvement, is increasing. An SSc phenotype-restricted genome-wide analysis was carried out recently [4]. Remarkably, two of the four new SSc genetic-susceptibility markers identified in the previously mentioned study might play a relevant role in the SSc-related fibrotic process, SOX5 and NOTCH4 [4]. However, no such strategy has yet been considered for pulmonary involvement, and only some studies have reported significant genetic association with SScrelated lung involvement [5-9]. Furthermore, only the association of $C D 226$ with pulmonary fibrosis has been

\section{Biomed Central}


independently replicated [10]. Wipff et al. [11] recently described the association of potassium voltage-gated channel shaker-related subfamily member 5 (KCNA5) with SSc-related pulmonary arterial hypertension (PAH).

Potassium voltage-gated channels (Kv channels) are homo- or heterotetramers of structural $\alpha$-subunits and regulatory $\beta$-subunits, which control potassium (K) flux. K balance is known to regulate the apoptotic cell shrinkage, a main event in the apoptotic process [12]. Specifically, KCNA5 participates in pulmonary artery smooth muscle cell (PASMC) apoptosis control [13]. It has been reported that overexpression of the KCNA5 gene induces accelerated $\mathrm{K}$ efflux and increases caspase- 3 proteolytic activity, promoting apoptosis [13].

KCNA5 is also involved in membrane-potential maintenance and vascular-tone regulation [14]. Hypoxic conditions produce a specific inhibition of KCNA5 in the PASMCs, causing pulmonary vasoconstriction [15-17]. Moreover, it has been reported that primary pulmonary hypertension patients have an intrinsic reduced level of KCNA5 mRNA in their PASMCs, and this characteristic might play an important role in the pathogenesis of the disease [18].

The role of KCNA5 genetic polymorphisms in pulmonary disease also was explored. Remillard et al. [19] analyzed the influence of KCNA5 genetic variants in IPAH, and showed that different single-nucleotide polymorphisms (SNPs) were related to abnormal function or drug responsiveness. Recently, the importance of KCNA5 variants in SSc-related PAH was analyzed [11]. In the previously mentioned study, the association of KCNA5 with SSc and specifically with PAH-positive $\left(\mathrm{PAH}^{+}\right)$patients was described [11]. Moreover, the rs 10744676 polymorphism was reported as the variant underlying the observed association [11].

In light of the previous evidence, the main goal of this report is to replicate the association of KCNA5 rs10744676 polymorphism with SSc and SSc-related PAH in an independent European population of Caucasian ancestry.

\section{Materials and methods \\ Subjects}

Our study comprised 2,343 SSc cases and 2,690 controls from Spain, The Netherlands, Italy, Sweden, and The United Kingdom. All the individuals included in this report were of Caucasian ancestry. Patients were classified as having limited (lcSSc) or diffuse SSc (dcSSc), according to their skin involvement, as defined by LeRoy et al. [20]. The serologic subgroup stratification of the patients was based on the presence of SSc-associated autoantibodies (anti-centromere antibodies (ACAs) and anti-topoisomerase (ATA)). Pulmonary fibrosis was diagnosed by the presence of interstitial abnormalities in high-resolution computed tomography (HRCT). Patients defined as $\mathrm{PAH}^{+}$showed a mean resting pulmonary artery pressure $>25 \mathrm{~mm} \mathrm{Hg}$ and a pulmonary capillary wedge pressure $\leq 15 \mathrm{~mm} \mathrm{Hg}$, at the time of a right-heart catheterization [11]. The control population consisted of unrelated healthy individuals recruited in the same geographic regions as the SSc patients and matched by age, sex, and ethnicity with the SSc-patient groups. Approval of local ethical committees was obtained from all the participating centers (Comite de Bioética del Consejo Superior de Investigaciones Científicas, Comitato Etico Azienda Ospedaliera Universitaria Integrata di Verona, Local Ethics Committee of the Radboud University Nijmegen Medical Centre, Medische Ethische Commissie Leids Universitair Medisch Centrum, The regional Ethical Review Board in Lund, Local Research Ethics Committee at Glasgow Royal Infirmary, U.O. Comitato di Etica e Sperimentazione Farmaci Fondazione IRCCS Ca' Granda-Ospedale Maggiore Policlinico di Milano, Local Research Ethics Committee at Glasgow Royal Infirmary, Royal Free Hospital and Medical School Research Ethics Committee, Manchester University Research Ethics Committee). Written informed consent was required for both patients and controls to be included in the study.

\section{Genotyping and statistical analysis}

The rs10744676 KCNA5 biallelic variant was analyzed with TaqMan SNP genotyping assay in a 7900HT RealTime polymerase chain reaction (PCR) system from Applied Biosystems by following the manufacturer's suggestions (Foster City, CA, USA).

None of the included cohorts showed significant deviation from Hardy-Weinberg equilibrium (HWE) ( $P$ value significance threshold, 0.05). Significance for the allelic model in the individual cohort analyses was calculated by $2 \times 2$ contingency tables and the Fisher Exact test or $\chi^{2}$ when necessary. Odds ratios (ORs) were calculated according to the Woolf method. A Breslow-Day test (BD test) was performed to assess the homogeneity of the association among populations, and pooled analysis under a Cochran-Mantel-Haenszel fixed-effect model was used to analyze jointly all the included cohorts. Statistical analyses were performed as implemented in PLINK (v1. 07) software package [21]. Power was calculated by using the software Power Calculator for Genetic Studies 2006 and assuming an additive model and previously reported minor allele frequency (MAF) and ORs [22].

\section{Results}

The power of our replication study in each stratified analysis is summarized in Table 1 . We emphasize that the size of our pooled $\mathrm{PAH}^{+}$patient subgroup represents the largest SSc-related $\mathrm{PAH}^{+}$cohort analyzed to date $(n=179)$. 
Table 1 Overall statistical power of the study for KCNA5 rs10744676 SNP in each analyzed disease subtype at the 5\% significance level assuming an additive effect model and a minor allele (rs10744676*C) frequency $=0.10$ (MAF ${ }_{\text {CEU }}$ )

\begin{tabular}{|c|c|c|c|c|c|c|c|}
\hline \multirow[b]{2}{*}{ Statistical power (\%) } & \multicolumn{7}{|c|}{ Phenotype } \\
\hline & SSc & IcSSc & dcSSc & $\mathrm{ACA}^{+}$ & ATA $^{+}$ & $\mathrm{Fib}^{+}$ & $\mathrm{PAH}^{+}$ \\
\hline $\mathrm{OR}=0.62$ & 100 & 100 & 99 & 100 & 96 & 99 & $95^{a}$ \\
\hline $\mathrm{OR}=0.48$ & 100 & 100 & 100 & 100 & 100 & 100 & $100^{\mathrm{b}}$ \\
\hline $\mathrm{OR}=0.79$ & 96 & 91 & 67 & 77 & 59 & 71 & $45^{c}$ \\
\hline
\end{tabular}

${ }^{\text {a }}$ Reference OR, 0.62, except for the $\mathrm{PAH}^{+}$group, in which $\mathrm{OR}=0.47 .{ }^{\mathrm{b}}$ Reference OR (lower previously reported $95 \% \mathrm{Cl}$ ) $=0.48$, except for the $\mathrm{PAH}{ }^{+}$group, in which OR $=0.32$. ' Reference OR (upper previously reported $95 \% \mathrm{Cl}$ ) $=0.79$, except for the PAH ${ }^{+}$group, in which OR $=0.71$. SSc, systemic sclerosis; IcSSc, limited cutaneous systemic sclerosis; dcSSc, diffuse cutaneous systemic sclerosis; ACA $^{+}$, anti-centromere autoantibody-positive patients; ATA $^{+}$, anti-topoisomerase autoantibody-positive patients; Fib $^{+}$, lung fibrosis-positive patients (HRCT); $\mathrm{PAH}^{+}$, pulmonary arterial hypertension-positive patients (right-heart catheterization)

The power of the study of this clinical feature in our population to detect an association equivalent to that previously reported by Wipff et al. is 95\%, at the 5\% significance level.

Table 2 shows the results of the comparison of the complete set of SSc and each of the previously defined subgroups with the healthy control group. As observed in the table, the analyzed polymorphism showed no significant association with either the disease or any of the subsets, not even the PAH-positive group. Furthermore, no significant association was observed in the individual population analyses, either in the whole disease comparison or in the different subphenotypes (see Additional file 1, Table S1). The different cohorts showed a high interpopulation combinability, as can be observed in the Breslow-Day test results (Table 2).

The minor allele in the Spanish and Italian control populations included in this study was less frequent than that in the pooled population described by the Wipff et al. $\left(\mathrm{rs}_{10744676^{*} \mathrm{C} \text { Frequency }}\right.$ Spain $=10.48 \%$; rs $10744676 * \mathrm{C}$ Frequency ${ }_{\text {Italy }}=10.00 \%$; rs $10744676 * \mathrm{C}$ Frequency pooled_wipff $\left._{\text {ind }} 14.7 \%\right)$. However, these frequencies are in concordance with those reported for the HapMap CEU population $\left(\mathrm{MAF}_{\text {HapMap_CEU }}=10.00 \%\right)$. Moreover, MAF differences have been reported in different European populations $\left(\mathrm{MAF}_{1000 \mathrm{Genomes} \mathrm{CEU}}=\right.$ $17.64 \%, \mathrm{MAF}_{1000 \mathrm{Genomes} \text { GBR }}=15.73 \%, \mathrm{MAF}_{1000 \mathrm{Genomes}}$ _FIN $=13.98 \%$, MAF $\left._{1000 \text { Genomes_TSI }}=8.16 \%\right)$.

In addition, the analysis of $\mathrm{PAH}^{+}$versus $\mathrm{PAH}^{-}$patients revealed no phenotype-restricted association in this subgroup $\left(P_{\mathrm{MH}}=0.59 ; \mathrm{OR}, 0.91 ; 95 \% \mathrm{CI}, 0.64\right.$ to 1.28$)$.

\section{Discussion}

Despite the previous findings of an association of the rs10744676 KCNA5 genetic variant with $\mathrm{PAH}^{+} \mathrm{SSc}$ patients, our data do not corroborate the reported protective effect of the minor allele of this polymorphism on SSc-related PAH.

It is worth mentioning that the prevalence of right-heart catheterization-confirmed $\mathrm{PAH}$ in our pooled population (7.64\%) is consistent with previous reports [11]. However, $\mathrm{SSc}$ is a chronic progressive disease, and some patients classified as $\mathrm{PAH}^{-}$might develop $\mathrm{PAH}$ in the future. Therefore, we consider this issue a limitation of our study and similar reports. In this context, we point out that the mean disease duration for the patient group included in this study (mean disease duration, $13.9 \pm 14.4$ years, as reported in Bossini-Castillo et al. [23]) was higher than that in Wipff et al. [11] (11.9 \pm 9.4 years in the discovery

Table 2 Pooled analysis and stratified analyses of SSc patients and healthy controls for rs10744676 genetic variant, located in the KCNA5 gene

\begin{tabular}{|c|c|c|c|c|c|c|c|}
\hline \multirow[b]{2}{*}{ Subgroup (n) } & \multicolumn{3}{|c|}{ Genotype, $n$ (\%) } & \multirow[b]{2}{*}{ MAF (\%) } & \multicolumn{3}{|c|}{ Allele test } \\
\hline & $\mathrm{C} / \mathrm{C}$ & $\mathrm{C} / \mathrm{T}$ & $\mathrm{T} / \mathrm{T}$ & & $P_{\mathrm{MH}}$ & OR $(95 \% \mathrm{Cl})$ & $P_{\mathrm{BD}}$ \\
\hline Controls $(n=2,690)$ & $37(1.38)$ & $597(22.19)$ & $2,056(76.43)$ & 12.47 & & & \\
\hline $\operatorname{SSC}(n=2,343)$ & $43(1.84)$ & $471(20.10)$ & $1,829(78.06)$ & 11.89 & 0.49 & $0.96(0.85-1.08)$ & 0.53 \\
\hline $\operatorname{lcSSc}(n=1,642)$ & $31(1.89)$ & $327(19.91)$ & $1,284(78.20)$ & 11.85 & 0.48 & $0.95(0.83-1.09)$ & 0.63 \\
\hline $\operatorname{dcSSc}(n=701)$ & $12(1.71)$ & $144(20.54)$ & $545(77.75)$ & 11.98 & 0.80 & $0.98(0.81-1.17)$ & 0.59 \\
\hline $\mathrm{ACA}^{+}(n=931)$ & $18(1.93)$ & $197(21.16)$ & $716(76.91)$ & 12.51 & 0.49 & $1.06(0.90-1.24)$ & 0.96 \\
\hline $\mathrm{ATA}+(n=568)$ & $8(1.41)$ & $117(20.60)$ & $443(77.99)$ & 11.71 & 0.85 & $0.98(0.80-1.20)$ & 0.94 \\
\hline $\mathrm{Fib}^{+}(n=771)$ & $14(1.82)$ & $154(19.97)$ & $603(78.21)$ & 11.80 & 0.34 & $0.92(0.77-1.09)$ & 0.92 \\
\hline $\mathrm{PAH}^{+}(n=179)$ & $2(1.12)$ & $37(20.67)$ & $140(78.21)$ & 11.45 & 0.44 & $0.88(0.63-1.23)$ & 0.70 \\
\hline
\end{tabular}

MAF, minor allele frequency; $P_{\mathrm{MH}}$, Mantel-Haenszel test under fixed-effect $P$ values. Controls are used as reference for all comparisons, and $P$ values have been calculated for the allelic model. OR, odds ratio for the minor allele; $95 \% \mathrm{Cl}$, 95\% confidence interval; SSc, systemic sclerosis; IcSSc, limited cutaneous systemic sclerosis; dcSSc, diffuse cutaneous systemic sclerosis; $\mathrm{ACA}^{+}$, anti-centromere autoantibody-positive patient; $\mathrm{ATA}^{+}$, anti-topoisomerase autoantibody-positive patient; $\mathrm{Fib}^{+}$, lung fibrosis-positive patient $(\mathrm{HRCT}) ; \mathrm{PAH}^{+}$, pulmonary arterial hypertension-positive patients (right-heart catheterization). 
cohort and $13.9 \pm 14.4$ years in the replication), which might influence the observed differences.

The $\mathrm{PAH}^{+}$cohort studied in this report reached a 95\% estimated statistical power to detect an association equivalent to that observed by Wipff et al. within this subgroup (OR, 0.47, in the comparison between $\mathrm{PAH}^{+}$SSc patients and controls of the discovery phase and two replication steps [11]). Hence, we consider that the lack of replication observed in our study is unlikely to be caused by a type II error (false negative) because of a reduced statistical power. However, autoimmune-associated variants usually show modest degrees of risk, especially in the case of nonHLA loci [24]. Wipff et al. reported an OR for KCNA5 rs10744676 polymorphism that was remarkably more protective than the SSc genetic-association standards for nonHLA loci (that is, modest ORs between 0.70 and 1). Thus, we reflect that if the influence of rs10744676 in the SScpatient genetic predisposition to PAH is modest, the statistical power to detect a possible association in the $\mathrm{PAH}^{+}$ cohort analyzed in the present article might be insufficient, and a possible modest effect of KCNA5 rs10744676 might be overlooked (Table 1).

In addition, it is established that PAH is more frequent in $\mathrm{ACA}^{+}$patients [1], and despite the suggestive association with $\mathrm{PAH}^{+}$patients, no significant association with the $\mathrm{ACA}^{+}$subphenotype was identified in the previous SSc study [11] or in this report. This fact is also consistent with a lack of association of the selected polymorphism with PAH development.

Although rs10744676 might have a functional role in KCNA5 expression because of its location in its putative promoter, no evidence confirms a functional role for this variant. Therefore, we speculate that the previously mentioned association with SSc could be the consequence of a tagged causal variant yet to be discovered. Moreover, because PAH onset time has not been considered for the analyses, it might act as a confounding factor in the discrepant results.

\section{Conclusions}

In summary, our data do not support an important role of rs10744676 as a PAH genetic marker in SSc patients.

\section{Additional material}

Additional file 1: Genotype and minor allele frequencies of KCNA5 rs 10744676 genetic variant in five European cohorts. This file contains Table S1, showing the genotype and allele distributions of KCNA5 rs 10744676 genetic variant in five European cohorts (2,343 SSC cases and 2,690 controls).

\section{Abbreviations}

ACA: anti-centromere autoantibodies; ATA: anti-topoisomerase antibodies; BD test: Breslow-Day test; CD226: cluster of differentiation 226; CEU: Utah residents with ancestry from northern and western Europe; dcSSc: diffuse cutaneous systemic sclerosis; hRCT: High-resolution computed tomography; HWE: Hardy-Weinberg equilibrium; K: potassium; KCNA5: potassium voltagegated channel shaker-related subfamily member 5; Kv channels: potassium voltage-gated channels; ICSSc: limited cutaneous systemic sclerosis; MAF: minor allele frequency; NOTCH4: Notch (Drosophila) homologue 4; OR: odds ratio; PAH: pulmonary arterial hypertension; PASMC: pulmonary artery smooth muscle cell; PCR: polymerase chain reaction; SNP: single-nucleotide polymorphism; SOX5: SRY (sex-determining region Y)-box 5; SSc: systemic sclerosis.

\section{Authors' contributions}

LBC contributed to the analysis and interpretation of data and to the drafting of the manuscript. CPS, LB, and JB participated in the acquisition of data and the drafting of the manuscript. CF, TRDJR, and JM contributed to the conception and design of the study and critically revised the manuscript. MCV, JLC, PC, LRR, RGP, MAGG, IC, MTC, CT, EVR, MVE, AJS, RH, $C L$, JMvL, PS, AH, JW, CD, and the Spanish Scleroderma Group were involved in the acquisition of data and the revision of the manuscript. All authors read and approved the final manuscript.

\section{Competing interests}

The authors declare that they have no competing interests.

\section{Acknowledgements}

We thank Sofia Vargas, Sonia García, and Gema Robledo for excellent technical assistance and all the patients and control donors for their essential collaboration. We thank Banco Nacional de ADN (University of Salamanca, Spain), who supplied part of the control DNA samples. We are also thankful to EUSTAR (The EULAR Scleroderma Trials and Research group for the facilitation of this project. We thank the following Spanish Scleroderma Group members for their contribution in this study: Norberto Ortego-Centeno and Raquel Ríos, Unidad de Enfermedades Sistémicas Autoinmunes, Servicio de Medicina Interna, Hospital Clínico Universitario San Cecilio, Granada; Nuria Navarrete, Servicio de Medicina Interna, Hospital Virgen de las Nieves, Granada; Antonio Fernández-Nebro, Servicio de Medicina Reumatología, Hospital Carlos Haya, Málaga; María F. GonzálezEscribano, Servicio de Inmunología, Hospital Virgen del Rocío, Sevilla; Julio Sánchez-Román, Ma Jesús Castillo and Francisco José García-Hernández, Servicio de Medicina Interna, Hospital Virgen del Rocío, Sevilla; Ma Ángeles Aguirre and Inmaculada Gómez-Gracia, Servicio de Reumatología, Hospital Reina Sofía, Córdoba; Benjamín Fernández-Gutiérrez, Servicio de Reumatología, Hospital Clínico San Carlos, Madrid; José Luis Andreu and Mónica Fernández de Castro, Servicio de Reumatología, Hospital Puerta del Hierro, Madrid; Paloma García de la Peña, Servicio de Reumatología, Hospital Madrid Norte Sanchinarro, Madrid; Francisco Javier López-Longo and Lina Martínez, Servicio de Reumatología, Hospital General Universitario Gregorio Marañón, Madrid; Vicente Fonollosa, Servicio de Medicina Interna, Hospital Valle de Hebrón, Barcelona; Gerard Espinosa, Servicio de Medicina Interna, Hospital Clinic, Barcelona; Anna Pros, Servicio de Reumatología, Hospital Del Mar, Barcelona; Mónica Rodríguez Carballeira, Servicio de Medicina Interna, Hospital Universitari Mútua Terrasa, Barcelona; Francisco Javier Narváez, Servicio de Reumatología, Hospital Universitari de Bellvitge, Barcelona; Bernardino Díaz, Luis Trapiella and María Gallego, Servicio de Medicina Interna, Hospital Central de Asturias, Oviedo; María del Carmen Freire and Inés Vaqueiro, Unidad de Trombosis y Vasculitis, Servicio de Medicina Interna, Hospital Xeral-Complexo Hospitalario Universitario de Vigo, Vigo; Luis Sáez-Comet, Unidad de Enfermedades Autoinmunes Sistémicas, Servicio de Medicina Interna, Hospital Universitario Miguel Servet, Zaragoza; Federico Díaz and Vanesa Hernández, Servicio de Reumatología, Hospital Universitario de Canarias, Tenerife; Juan José Alegre, Servicio de Reumatología, Hospital del Doctor Peset Aleixandre, Valencia; José Andrés Román-Ivorra, Servicio de Reumatología, Hospital Universitari i Politecnic La Fe, Valencia. Francisco J. Blanco-García and Natividad Oreiro, Servicio de Reumatología, INIBIC-Hospital Universitario A Coruña, La Coruña.

This work was supported by the following grants: JM was funded by GENFER from the Spanish Society of Rheumatology, SAF2009-11110 from the Spanish Ministry of Science, CTS-4977 from Junta de Andalucía, Spain, in part by Redes Temáticas de Investigación Cooperativa Sanitaria Program, RD08/ 0075 (RIER) from Instituto de Salud Carlos III (ISCIII), Spain, and by Fondo Europeo de Desarrollo Regional (FEDER). TRDJR was funded by the VIDI 
laureate from the Dutch Association of Research (NWO) and Dutch Arthritis Foundation (National Reumafonds). JM and TRDJR were sponsored by the Orphan Disease Program grant from the European League Against Rheumatism (EULAR). BPCK is supported by the Dutch Diabetes Research Foundation (grant 2008.40.001) and the Dutch Arthritis Foundation (Reumafonds, grant NR 09-1-408). This study was also funded by PI-05902010, Consejería de Salud, Junta de Andalucía, Spain.

\section{Author details}

'Instituto de Parasitología y Biomedicina López-Neyra, IPBLN-CSIC, Avenida del Conocimiento s/n, Granada, 18100, Spain. ${ }^{2}$ Servicio de Medicina Interna, Hospital Valle de Hebron, Passeig de la Vall d'Hebron, 119-129, Barcelona, 08035, Spain. ${ }^{3}$ Referral Center for Systemic Autoimmune Diseases Fondazione IRCCS Ca' Granda Ospedale Maggiore Policlinico di Milano, via Francesco Sforza 28, Milan, 20122, Italy. ${ }^{4}$ Department of Rheumatology \& Clinical Immunology, University Medical Center, Heidelberglaan 100, 3485 CX Utrecht, The Netherlands. ${ }^{5}$ Laboratory of Translational Immunology, University Medical Center, Heidelberglaan 100, 3485 CX Utrecht, The Netherlands. ${ }^{6}$ Department of Rheumatology, Radboud University Nijmegen Medical Centre, Geert Grooteplein-Zuid 10, Nijmegen, 6525 GA, The Netherlands. "'Servicio de Medicina Interna, Hospital Clínico Universitario, Avenida Doctor Olóriz 16, Granada, 18012, Spain. ${ }^{8}$ Servicio de Reumatología, Hospital Universitario 12 de Octubre, Avenida de Córdoba, s/n, Madrid, 28041, Spain. ${ }^{9}$ Servicio de Reumatología, Hospital Clínico San Carlos, C/ Profesor Martín Lagos s/n, Madrid, 28040, Spain. ${ }^{10}$ Servicio de Reumatología, Hospital Universitario Virgen de la Victoria, Campus Universitario Teatinos s/ n, Málaga, 29010, Spain. ${ }^{11}$ Servicio de Reumatología, Hospital Universitario Marqués de Valdecilla, IFIMAV, Avenida Valdecilla 25, Santander, 39008, Spain. ${ }^{12}$ Servicio de Reumatología, Hospital de la Santa Creu i Sant Pau, C/Sant Antoni Maria Claret 167, Barcelona, 08025, Spain. ${ }^{13}$ Servicio de Medicina Interna, Hospital Carlos Haya, Avenida Carlos Haya s/n, Málaga, 29010, Spain. ${ }^{14}$ Servicio de Medicina Interna, Hospital Parc Tauli, Parc del Taulí 1, Sabadell, 08208, Spain. ${ }^{15}$ Servicio de Reumatología, Hospital Universitario de la Princesa, C Diego de León 62, Madrid, 28006, Spain. ${ }^{16}$ Servicio de Medicina Interna, Hospital de Cruces, Plaza de Cruces 2, Barakaldo, 48903, Spain. ${ }^{17}$ Department of Rheumatology, Leiden University Medical Center, Albinusdreef 2, Leiden, 2333 ZA, The Netherlands. ${ }^{18}$ Department of Rheumatology, Lund University, Paradisgatan 2, Lund, SE-221 00, Sweden. ${ }^{19}$ Department of Medicine, Università degli Studi di Verona, Via dell'Artigliere 19, Verona, 37129, Italy. ${ }^{20}$ Institute of Cellular Medicine, Newcastle University, Framlington Place, Newcastle upon Tyne, Newcastle, NE2 4HH, UK. ${ }^{21}$ Centre for Rheumatic Diseases, Glasgow Royal Infirmary, 84 Castle Street, Glasgow G4 OSF, UK. ${ }^{22}$ Arthritis Research UK Epidemiology Unit, The University of Manchester, Manchester Academic Health Science Centre, Stopford Building, Oxford Road, Manchester, M13 9PT, UK. ${ }^{23}$ Centre for Rheumatology, Royal Free and University College Medical School, University College London, Royal Free Campus, Rowland Hill Street, London, NW3 PF, UK.

Received: 16 July 2012 Revised: 6 December 2012

Accepted: 20 December 2012 Published: 27 December 2012

\section{References}

1. Gabrielli A, Avvedimento EV, Krieg T: Scleroderma. N Engl J Med 2009, 360:1989-2003.

2. Steen VD, Medsger TA: Changes in causes of death in systemic sclerosis, 1972-2002. Ann Rheum Dis 2007, 66:940-944.

3. Martin JE, Bossini-Castillo L, Martin J: Unraveling the genetic component of systemic sclerosis. Hum Genet 2012, 131:1023-1037.

4. Gorlova O, Martin JE, Rueda B, Koeleman BP, Ying J, Teruel M, DiazGallo LM, Broen JC, Vonk MC, Simeon CP, Alizadeh BZ, Coenen MJ, Voskuyl AE, Schuerwegh AJ, van Riel PL, Vanthuyne M, van 't Slot $R$, Italiaander A, Ophoff RA, Hunzelmann N, Fonollosa V, Ortego-Centeno N, Gonzalez-Gay MA, Garcia-Hernandez FJ, Gonzalez-Escribano MF, Airo P, van Laar J, Worthington J, Hesselstrand R, Smith V, et al: Identification of novel genetic markers associated with clinical phenotypes of systemic sclerosis through a genome-wide association strategy. PLoS Genet 2011, 7:e1002178.

5. Dieude P, Guedj M, Wipff J, Ruiz B, Hachulla E, Diot E, Granel B, Sibilia J, Tiev K, Mouthon L, Cracowski JL, Carpentier PH, Amoura Z, Fajardy I, Avouac J, Meyer O, Kahan A, Boileau C, Allanore Y: STAT4 is a genetic risk factor for systemic sclerosis having additive effects with IRF5 on disease susceptibility and related pulmonary fibrosis. Arthritis Rheum 2009, 60:2472-2479.

6. Dieude P, Guedj M, Wipff J, Ruiz B, Riemekasten G, Airo P, Melchers I, Hachulla E, Cerinic MM, Diot E, Hunzelmann N, Caramaschi P, Sibilia J, Tiev K, Mouthon L, Riccieri V, Cracowski JL, Carpentier PH, Distler J, Amoura Z, Tarner I, Avouac J, Meyer O, Kahan A, Boileau C, Allanore Y: NLRP1 influences the systemic sclerosis phenotype: a new clue for the contribution of innate immunity in systemic sclerosis-related fibrosing alveolitis pathogenesis. Ann Rheum Dis 2011, 70:668-674.

7. Dieude P, Guedj M, Wipff J, Ruiz B, Riemekasten G, Matucci-Cerinic M, Melchers I, Hachulla E, Airo P, Diot E, Hunzelmann N, Cabane J, Mouthon L, Cracowski JL, Riccieri V, Distler J, Meyer O, Kahan A, Boileau C, Allanore Y: Association of the TNFAIP3 rs5029939 variant with systemic sclerosis in the European Caucasian population. Ann Rheum Dis 2010, 69:1958-1964.

8. Hoshino K, Satoh T, Kawaguchi Y, Kuwana M: Association of hepatocyte growth factor promoter polymorphism with severity of interstitial lung disease in Japanese patients with systemic sclerosis. Arthritis Rheum 2011, 63:2465-2472.

9. Dieude P, Guedj M, Truchetet ME, Wipff J, Revillod L, Riemekasten G, Matucci-Cerinic M, Melchers I, Hachulla E, Airo P, Diot E, Hunzelmann N, Mouthon L, Cabane J, Cracowski JL, Riccieri V, Distler J, Amoura Z, Valentini G, Camaraschi P, Tarner I, Frances C, Carpentier P, Brembilla NC, Meyer O, Kahan A, Chizzolini C, Boileau C, Allanore Y: Association of the CD226 Ser(307) variant with systemic sclerosis: evidence of a contribution of costimulation pathways in systemic sclerosis pathogenesis. Arthritis Rheum 2011, 63:1097-1105.

10. Bossini-Castillo L, Simeon CP, Beretta L, Broen JC, Vonk MC, RiosFernandez R, Espinosa G, Carreira P, Camps MT, Castillo MJ, GonzalezGay MA, Beltran E, Carmen Freire MD, Narvaez J, Tolosa C, Witte T, Kreuter A, Schuerwegh AJ, Hoffmann-Vold AM, Hesselstrand R, Lunardi C, van Laar JM, Chee MM, Herrick A, Koeleman BP, Denton CP, Fonseca C, Radstake TR, Martin J: A multicenter study confirms CD226 gene association with systemic sclerosis-related pulmonary fibrosis. Arthritis Res Ther 2012, 14:R85.

11. Wipff J, Dieude P, Guedj M, Ruiz B, Riemekasten G, Cracowski JL, MatucciCerinic M, Melchers I, Humbert M, Hachulla E, Airo P, Diot E, Hunzelmann N, Caramaschi P, Sibilia J, Valentini G, Tiev K, Girerd B, Mouthon L, Riccieri V, Carpentier PH, Distler J, Amoura Z, Tarner I, Degano B, Avouac J, Meyer O, Kahan A, Boileau C, Allanore Y: Association of a KCNA5 gene polymorphism with systemic sclerosis-associated pulmonary arterial hypertension in the European Caucasian population. Arthritis Rheum 2010, 62:3093-3100.

12. Bortner CD, Hughes FM Jr, Cidlowski JA: A primary role for $\mathrm{K}^{+}$and $\mathrm{Na}^{+}$ efflux in the activation of apoptosis. J Biol Chem 1997, 272:32436-32442.

13. Brevnova EE, Platoshyn O, Zhang S, Yuan JX: Overexpression of human KCNA5 increases IK V and enhances apoptosis. Am J Physiol Cell Physiol 2004, 287:C715-722.

14. Yuan $\mathrm{XJ}$ : Voltage-gated $\mathrm{K}^{+}$currents regulate resting membrane potential and $\left[\mathrm{Ca}^{2+}\right]_{\mathrm{i}}$ in pulmonary arterial myocytes. Circ Res 1995, 77:370-378.

15. Archer SL, Souil E, Dinh-Xuan AT, Schremmer B, Mercier JC, El Yaagoubi A, Nguyen-Huu L, Reeve HL, Hampl V: Molecular identification of the role of voltage-gated $\mathrm{K}^{+}$channels, Kv1.5 and Kv2.1, in hypoxic pulmonary vasoconstriction and control of resting membrane potential in rat pulmonary artery myocytes. J Clin Invest 1998, 101:2319-2330.

16. Platoshyn O, Brevnova EE, Burg ED, Yu Y, Remillard CV, Yuan JX: Acute hypoxia selectively inhibits KCNA5 channels in pulmonary artery smooth muscle cells. Am J Physiol Cell Physiol 2006, 290:C907-C916.

17. Coppock EA, Martens JR, Tamkun MM: Molecular basis of hypoxia-induced pulmonary vasoconstriction: role of voltage-gated $\mathrm{K}^{+}$channels. Am J Physiol Lung Cell Mol Physiol 2001, 281:L1-L12.

18. Yuan XJ, Wang J, Juhaszova M, Gaine SP, Rubin LJ: Attenuated K ${ }^{+}$channel gene transcription in primary pulmonary hypertension. Lancet 1998, 351:726-727.

19. Remillard CV, Tigno DD, Platoshyn O, Burg ED, Brevnova EE, Conger D, Nicholson A, Rana BK, Channick RN, Rubin LJ, O'Connor DT, Yuan JX: Function of Kv1.5 channels and genetic variations of KCNA5 in patients with idiopathic pulmonary arterial hypertension. Am J Physiol Cell Physiol 2007, 292:C1837-C1853.

20. LeRoy EC, Black C, Fleischmajer R, Jablonska S, Krieg T, Medsger TA Jr, Rowell N, Wollheim F: Scleroderma (systemic sclerosis): classification, subsets and pathogenesis. J Rheumatol 1988, 15:202-205. 
21. Purcell S, Neale B, Todd-Brown K, Thomas L, Ferreira MA, Bender D, Maller J, Sklar P, de Bakker PI, Daly MJ, Sham PC: PLINK: a tool set for wholegenome association and population-based linkage analyses. Am J Hum Genet 2007, 81:559-575.

22. Skol AD, Scott $L$, Abecasis GR, Boehnke M: Joint analysis is more efficient than replication-based analysis for two-stage genome-wide association studies. Nat Genet 2006, 38:209-213.

23. Bossini-Castillo L, Simeon CP, Beretta L, Vonk MC, Callejas-Rubio JL, Espinosa G, Carreira P, Camps MT, Rodriguez-Rodriguez L, RodriguezCarballeira M, Garcia-Hernandez FJ, Lopez-Longo FJ, HernandezHernandez V, Saez-Comet L, Egurbide MV, Hesselstrand R, Nordin A, Hoffmann-Vold AM, Vanthuyne M, Smith V, De Langhe E, Kreuter A, Riemekasten G, Witte T, Hunzelmann N, Voskuyl AE, Schuerwegh AJ, Lunardi C, Airo P, Scorza R, et al: Confirmation of association of the macrophage migration inhibitory factor gene with systemic sclerosis in a large European population. Rheumatology (Oxford) 2011, 50:1976-1981.

24. Cho JH, Gregersen PK: Genomics and the multifactorial nature of human autoimmune disease. N Engl I Med 2011, 365:1612-1623.

doi:10.1186/ar4124

Cite this article as: Bossini-Castillo et al: KCNA5 gene is not confirmed as a systemic sclerosis-related pulmonary arterial hypertension genetic susceptibility factor. Arthritis Research \& Therapy 2012 14:R273.

\section{Submit your next manuscript to BioMed Central} and take full advantage of:

- Convenient online submission

- Thorough peer review

- No space constraints or color figure charges

- Immediate publication on acceptance

- Inclusion in PubMed, CAS, Scopus and Google Scholar

- Research which is freely available for redistribution

Submit your manuscript at www.biomedcentral.com/submit 